Article

\title{
Explainable Post-Occupancy Evaluation Using a Humanoid Robot
}

\author{
Marina Bonomolo $^{1}$ (D), Patrizia Ribino ${ }^{2}$ (D) and Gianpaolo Vitale ${ }^{2, *(D)}$ \\ 1 Dipartimento di Ingegneria, Università degli Studi di Palermo, 90128 Palermo, Italy; \\ marina.bonomolo@deim.unipa.it \\ 2 Institute for High Performance Computing and Networking, National Research Council, \\ 90146 Palermo, Italy; patrizia.ribino@icar.cnr.it \\ * Correspondence: gianpaolo.vitale@icar.cnr.it
}

Received: 28 September 2020; Accepted: 5 November 2020; Published: 7 November 2020

check for updates

\begin{abstract}
The paper proposes a new methodological approach for evaluating the comfort condition using the concept of explainable post occupancy to make the user aware of the environmental state in which (s)he works. Such an approach was implemented on a humanoid robot with social capabilities that aims to enforce human engagement to follow recommendations. The humanoid robot helps the user to position the sensors correctly to acquire environmental measures corresponding to the temperature, humidity, noise level, and illuminance. The distribution of the last parameter due to its high variability is also retrieved by the simulation software Dialux. Using the post occupancy evaluation method, the robot also proposes a questionnaire to the user for collecting his/her preferences and sensations. In the end, the robot explains to the user the difference between the suggested values by the technical standards and the real measures comparing the results with his/her preferences and perceptions. Finally, it provides a new classification into four clusters: true positive, true negative, false positive, and false negative. This study shows that the user is able to improve her/his condition based on the explanation given by the robot.
\end{abstract}

Keywords: explainable post occupancy; humanoid robot; lighting simulation software

\section{Introduction}

The improvement of comfort conditions is one of the main goals for an optimal building design. Many standards and studies propose methods and indices to evaluate the quality of the environment [1-4]. They indicate methods and criteria for the design of indoor environments and the evaluation of the energetic performance of buildings related to the internal air quality, illuminance level, and thermal and acoustic parameters. In general, such standards are based on measurable values directly collected from the environment by employing appropriate sensors.

It is also widely recognized that comfort perception is mostly influenced by the psychological and physiological aspects of the users, as was shown in [5-11], where the Post Occupancy Evaluation (POE) approach was proposed as a suitable method for evaluating user's subjective aspects. However, traditional approaches for evaluating and reaching comfort situations show some drawbacks.

Firstly, the location of the sensors used for measuring or controlling systems can influence the reliability of the measurement [12] or the performance of the control system [13]. Indeed, the monitoring campaign of the environmental parameters in indoor spaces is commonly carried out using weather stations generally placed in the middle of the room [14-16]. Such position sometimes impede the collection of the measures close to the users as the standards claim. It can jeopardize the reliability of the measures. For example, the illuminance values should be measured on the work-plane as suggested by the EN12464 standard [17] or by the standard ISO 8995 [4]. Hence, the fixed location of the sensors 
may downgrade the performance of the adopted environmental control system. Moreover, because a building can have a different organization of the fixtures, the position of the station could disturb the user. Some recently published papers faced this problem by proposing different solutions based on environmental sensors [18], sensors aided by correlation and regression analysis [19], or by optimization algorithms (GA and RBF-NN) [20].

Secondly, a widely used method for reaching comfort conditions is based on Building Automation and Control Systems (BACSs). A BACS automatically gathers data related to environmental parameters, and it takes appropriate corrective actions to maintain the reference values established by the standard. It has been recently noted that the use of such systems may cause some discomfort to the building occupant [21-23]. This is generally due to the loss of control that users perceive [23], in particular when they are not aware of the reasons that induced the system to change the environmental conditions. Indeed, such systems generally do not give feedback to the users, which often do not understand the behavior adopted by the system [5,6]. Thirdly, BACSs use a dense array of sensors, placed in fixed locations of the building, for collecting data at different points of the environment. Such an approach is costly, especially when implemented in old existing buildings.

Finally, long-term measurement is the most effective and accurate way to establish databases that contain this information [24]. However, it is unfeasible to purchase and install pyranometers and illuminance meters at every orientation and tilted angle to collect all of the required data [24]. If it is not suitable to place a grid of sensors, support can be given by simulation software [25].

In this work, we propose a new methodological approach, which, addressing the drawbacks mentioned above, extends the approach proposed in [26], where a method for reaching comfort conditions was presented. The need to improve such an approach comes from retrieving information given by highly fluctuating parameters both in space and in time, such as the illuminance. Moreover, the users' consciousness and their acceptance of supporting technology were further enhanced by giving a comprehensive explanation during the interaction, transforming the traditional POE approach into Explainable POE (EPOE). Notably, the explanation is based on four kinds of possible results: (1) False Positive (FP): the environment does not comply with the standard, and the user feels good; (2) True Negative (TN): the environment does not comply with the standard, and the user does not feel good; (3) False Negative (FN): the environment complies with the standard, and the user is not feeling well; and finally (4) True Positive (TP): the environment complies with the standard, and the user feels good.

Hence, the proposed approach is founded on a new triplet of elements: (i) a humanoid robot for carrying out the application of the measurements of the environmental parameters; (ii) a POE questionnaire performed by the robot; (iii) a simulation lightning software for reproducing the trend of the light distribution both in the space and during the hours of the day. Each element was chosen to face some limitations of the traditional approaches and the particular strengths they provide.

Although the use of a robot for collecting environmental data was firstly introduced in [27-29], they did not resolve the issue of acquiring the measurement at particular positions because they are not reachable by the robot. We chose to adopt a humanoid social robot both to exploit its mobility for collecting measures, as well as to take advantage of human cooperation to locate sensors opportunely. Indeed, it has been demonstrated that both the physical and the anthropomorphic nature of humanoid social robots improves human engagement $[30,31]$. Humans are more pleasantly involved in their collaboration with robots that are socially competent and show humans traits. Moreover, it should be remarked that the use of humanoid robots strengthens the concept of explainability, as will be evident in the paper.

The significant contribution of this paper is a new methodological approach based on a humanoid robot along with a simulation lightning software for improving indoor comfort conditions and user awareness of his/her environment and cooperation in the control process. The robot collecting and reasoning on four kinds of information (environmental parameters, user preferences from POE, 
data from the simulation software, and recommendations from the standards) provides a final report. It includes the comfort conditions of the user under analysis and some suggestions to improve them.

The rest of the paper is organized as follows. Section 2 is devoted to explaining the analogies to and differences from the literature and to putting in evidence the novelties of the proposed approach. Section 3 introduces the proposed methodological approach. Section 4 illustrates the case study, and finally, Section 5 contains the conclusions.

\section{Related Work}

The literature shows a strong interest in the issues discussed in this paper. Indeed, several papers dealing with the topic inherent to our work have been recently published. Some of these are directly related to the Indoor Environment Quality (IEQ) $[18,19,23,32-36]$ and the relevance of the appropriate location of sensors [12,13], while others analyzed the impact of lighting control on workers' health in-depth $[20,37-40]$ and exploited a robot $[28,29]$, whereas the issues related to the post occupant evaluation were studied in [5-10]. The approach proposed in this paper shows similarities and differences compared to the above-mentioned research. To focus on the novelty of this work, a detailed comparison is performed in the following.

Kallio et al. [18] proposed an approach based on relatively inexpensive sensors and exploited machine learning to assess the employees' perception of indoor environment quality, introducing a new method to classify the data. The approach proposed in [32] was based on a laboratory method. It consisted of a chamber in which thermal and luminous conditions could be varied. It was found that space, luminous, and thermal parameters positively affected the satisfaction of users; however, the influence of acoustic noise was not treated. Geng et al. [33] also considered the Energy Use Intensity (EUI) to estimate the performance of green structures, and the differences put in evidence by groups belonging to high and low EUI buildings were related to the energy used for the thermal environment according to the standards. In addition to the traditional approach based on a questionnaire, Tang et al. [19] used a correlation and regression analysis for predicting overall satisfaction. They exploited a laboratory approach with 31 prescribed sets of conditions. Different from this, Dunleavy et al. [34] investigated the difference between aboveground and underground work spaces in terms of psychological distress, and they considered a high number of samples, classified by the OFFICAIRquestionnaire, showing that different parameters influence the two categories.

Lu et al. [35] faced the problem of a personalized model for thermal comfort for people sharing the same offices by using infrared thermography to predict the thermal sensation of users. Sakellaris et al. [23] conducted a large-scale survey that raised the important role of personal control for IEQ satisfaction in office buildings. This study highlighted that personal control is a crucial aspect in obtaining a healthy, comfortable, and productive environment. Angelova and Velichkova [36] analyzed the problem of the thermo-physiological comfort of patients and surgeons in operating room where there was a conflict in the requirements for the thermal environment between the two categories of users. The analysis took into consideration factors related to clothing.

Bonomolo et al. [12] and Bellia et al. [13] explained that the position of the sensors could downgrade the performance of BACSs. As a consequence, data collection had to be done by locating the sensors at suitable points.

As in Bonomolo et al. [12] and Bellia et al. [13], in this paper, we underline the crucial aspect of the measurement points. Moreover, our paper agrees with the approach proposed by Kallio et al. [18] based on inexpensive sensors, as well as with the works proposed in [19,32-34], which collected data by questionnaire. Different from [18], we propose a robot endowed with a set of sensors. Compared to the others, our approach shows two main differences: (a) it aims to plan an interaction between the robot and the user for improving his/her conditions based on recommendations given by the robot; (b) it uses a dedicated software (aided by a few experimental values obtained by a sensor) to reproduce the illuminance. Besides, our paper describes a methodological approach; hence, the study of a great number of users and related analysis methods as in $[18,19,34]$ can be considered as a further 
step. The comparison with the standard, performed in [33], is improved in our paper based on the feedback provided by users, and new classification criteria are given (i.e., TP-FP-TN-FN) with the possibility given to the users to improve their condition in real time. Different from the laboratory approach of [19], our study is focused on real operating conditions.

As concerns the role of lighting discussed in [20,37-39], it is widely recognized as crucial to workers' health; our paper is focused on this as well, and the illuminance is retrieved by software based on a measurement point. Zanon et al. [40] proposed a new index for evaluating visual comfort based on quantitative and qualitative parameters, highlighting the advantage of using such an index in a simulation software, which allowed the simulation of several parameters with good accuracy. Pragmatic open-loop procedures were explained in [37], where open loops were recognized as more competent and as an alternative to closed-loop systems. Gao et al. [20] exploited a wireless sensors network to retrieve data related to illuminance. They aimed to reduce the number of sensors using an optimization algorithm (GA and RBF-NN) obtaining a matrix with illuminance data. Bellia et al. [38] investigated the impact of Percentage Light Oscillations (PDFs) on users and related switching techniques; the shading of the sensors placed near the windows was considered, but it was evaluated as not preferable. They concluded with the need to minimize the light oscillations even if the tolerance is still under study. In contrast, De Vries et al. [39] took into consideration the influence of wall luminance on an office.

Different from [37], the proposed paper aims to make the user aware of the optimal conditions defining the comfort, and as a consequence, the user is encouraged to adjust the control system according to the recommendation of the robot. Compared to [20], the target is the same, i.e., to obtain a precise reconstruction of the I-matrix. Nevertheless, Reference [20] obtained the I-matrix by a few static sensors and optimization algorithms. On the contrary, we propose the use of the Dialux software validated by a sensor placed on the user's work-plane aided by a robot. Our approach has the drawback of using commercial software. Still, on the other hand, it exploits a single measurement point, and it can model the elements of the environment precisely. Finally, the conclusions of [38,39], in our case, can be given to the user as further advice, thanks to the user-robot interaction.

The features of a robot to improve the knowledge of the environment were exploited in $[28,29,41]$. In [28], a high granularity of the data distribution was obtained by a mobile sensing platform; this is very different from our approach, which adopts a humanoid able to interact with a human. In our case, the questionnaire is filled during the interaction. Yang et al. [29] used a mobile platform, as did [28], to test different algorithms for contaminant detection. In [41], R.K. Mantha et al. used a mobile robot for collecting ambient parameter data in existing houses with the ultimate aim to retrieve an optimized building retrofit decision (e.g., energy saving).

These papers confirm the approach proposed in our work, meaning that a robot easily collects data; unfortunately, they do not resolve the issue of acquiring the measurement at specific positions not reachable by the robot. In our work, we adopt a robot with an anthropomorphic nature and social abilities for our purposes. In particular, the mobility and the attitude in the interaction with a human of a social humanoid robot allow us to collect measures in appropriate locations through human cooperation as well as to make how the comfort is retrieved explainable.

Indeed, as was demonstrated by recent studies, both the physical and anthropomorphic nature of a social robot have a positive effect on human engagement. In [42], the authors investigated the user's behavior with respect to accepting advice from a physical robot against a computer agent. They showed that a humanoid robot is more valuable in giving recommendations. In [43], the authors analyzed the abilities of a robot, compared to a virtual agent, to persuade human users in a task such as following indications, showing better trust and confidence for the physical robots. In [30], the authors compared a humanoid robot with a mobile application in order to understand the most suitable system for providing recommendations. Their study demonstrated that users prefer the assistance of a social robot. Reference [31] investigated the role of the robot's appearance concerning the acceptance of recommendations. Different humanoid robots were used to provide advertisements to customers at a 
shopping mall. Such a study proved that people are more attracted to small robots than large ones since the interaction with the small robots was considered more straightforward.

The POE was deeply studied in [5-11]. Yu et al. [11] analyzed the subjective and objective measurements of indoor environment quality from four points of views: thermal, visual, acoustic comfort, and indoor air quality. The entire set of data related to these studies was based on the analysis of habits related to energy consumption and control of the environment when Heating, Ventilation and Air Conditioning systems (HVACs) were used. The authors found the desire of users to learn more about how environment control systems work and comfort is provided. The analysis of our paper is based on the same parameters as in [11].

Pastore et al. [6] focused their attention on the relationship between building sustainability and comfort/health conditions. This underlines that the compliance to the standards does not always fit the users' satisfaction, and it was found that the limitations in individual thermal preference degrade the comfort perception. The gender differences in the perception of IEQ (thermal discomfort in particular) were investigated in [7]. Choi and Moon [8] encompassed questionnaire surveys, environmental measurements, and building attributes; a statistical analysis of them was performed. A "quality measurement car" was devised (this is similar to the mobile platform shown in [28]); the study revealed correlations between human factors and IEQ compliance. Despite the analysis of [9], referring to outdoor spaces, the integration of spatial and temporal data and the attention to the context were interesting; it was pointed out that the users' perspective must be considered from the design phase. The study proposed in [5] showed different IEQ perceptions due to age and gender (not to season, which seems bizarre, but this is probably due to the location in Southern California). Finally, the survey [10] collected a significant part of this information in a unique paper.

Our paper agrees with the papers in which individuals were considered part of the IEQ definition process, including her/his gender, age, and preferences. Our proposed approach takes into account these results when the robot gives the report to the user, and it provides recommendations to improve his/her comfort. In the case of true negatives or false positives, the advice given by the robot can help the user make a change in his/her habits or modify the environmental conditions.

\section{Explainable POE Approach}

The main goal of this work is the improvement of indoor comfort conditions by making the user aware of his/her situation. The proposed explainable POE approach exploits a humanoid robot that performs a POE survey, collects data, compares them with the standards, and gives an explanation to the user. The analysis performed by the lighting simulation software, which gives information on illuminance levels at different points of the environment, was one-off validated by some measures acquired on a grid of points placed on the user work-plane to verify the correctness of the implementation of both the furniture and lighting sources; then, in normal operating conditions, it was confirmed by a single validation point acquired by the robot. Finally, the robot explained to the user the differences between his/her perception and standards, and it gave information to improve compliance with the standard. In the following, the procedure is described in detail.

\subsection{Environmental Comfort}

Although the standards define comfort, its determination represents a quite difficult task because subjective factors influence it. Indeed, it depends on the perception of the world given by our five senses, leading to an individual perception of the degree of comfort. In this work, we take into consideration three kinds of comfort [44]: thermal, visual, and acoustic comfort.

- Thermal comfort: Thermal comfort depends on our perception of the environmental temperature. Our body performs within an internal temperature range much narrower than external temperatures. In particular, due to metabolism, heat is generated and transmitted to the external environment. High external temperatures hinder this process, and a warm sensation is perceived. 
Conversely, when external temperatures are low, a feeling of cold is experienced. Furthermore, the relative humidity plays a relevant role in providing the perception of thermal comfort. During frosty winters, high levels of relative humidity cause a more intense perception of cold. On the other hand, in hot environments, a greater sensation of warmth can be produced by high levels of humidity.

- Visual comfort: Visual comfort is related to the quantity and quality of light. Both insufficient and excessive intensity of light may cause visual discomfort. Visual comfort encompasses a variety of aspects, such as views of outdoor environments, the quality of light, as well as the lack of glare.

- Acoustic comfort: Acoustic comfort is achieved by minimizing noise. This improves concentration and allows for better communication.

Hence, the discomfort is experienced when the thresholds of the environmental parameters are approached. On the contrary, the sensation of comfort is mainly correlated with the ranges of the acceptability of such parameters. Several standards propose such ranges. In particular, ASHRAE 55-92 [3] is a standard that provides the recommended values of environmental parameters for thermal well-being, as is shown in Table 1.

Table 1. Comfort zones for the summer and winter seasons.

\begin{tabular}{ccccc}
\hline & \multicolumn{2}{c}{ Thresholds in SUMMER } & \multicolumn{2}{c}{ Thresholds in WINTER } \\
\hline Relative Humidity & Low Temp & High Temp & Low Temp & High Temp \\
\hline $30 \%$ & $24^{\circ} \mathrm{C}$ & $27^{\circ} \mathrm{C}$ & $20^{\circ} \mathrm{C}$ & $25^{\circ} \mathrm{C}$ \\
$60 \%$ & $23^{\circ} \mathrm{C}$ & $25^{\circ} \mathrm{C}$ & $20^{\circ} \mathrm{C}$ & $23^{\circ} \mathrm{C}$ \\
\hline
\end{tabular}

As concerns visual comfort, the European standard EN 12464-1 [17] defines the quantity and quality of illumination as lighting requirements for indoor work spaces. It covers offices, places of public assembly, restaurants/hotels, and theaters/cinemas. Moreover, recommended light levels are provided according to the task an individual has to perform. An example is provided in Table 2. Noise Rating (NR) [45] i as standard to measure and quantify noise in buildings. Table 3 reports an excerpt of the NR levels that are recommended for different application areas. Moreover, the mapping of NR levels with the sound pressure level expressed in decibels $(\mathrm{dB}$, the commonly used unit of measurement) is provided by the noise rating curves. For example, for spaces with office end-use, the maximum sound pressure level is $55 \mathrm{~dB}$.

Table 2. Examples of recommended light levels for offices.

\begin{tabular}{cc}
\hline Type of Activity & Illuminance \\
\hline Writing, typing, reading $\ldots$ & $500 \mathrm{~lx}$ \\
Technical design & $750 \mathrm{~lx}$ \\
Conference and meeting & $500 \mathrm{~lx}$ \\
Reception & $300 \mathrm{~lx}$ \\
\hline
\end{tabular}

Table 3. Maximum recommended noise rating levels.

\begin{tabular}{cc}
\hline Type of Application & Max Noise Rating Level \\
\hline Concert halls, broadcasting and recording studios, churches & NR 25 \\
Halls, shops cloakrooms, restaurants, night clubs, offices & NR 40 \\
Offices with business machines, typing pools & NR 50 \\
Foundries and heavy engineering works & NR 70 \\
\hline
\end{tabular}

\subsection{Data Acquisition}

As previously mentioned, the robot acquires data also from the environment and the user. The robot was equipped with wearable sensors to collect environmental data. As previously said, 
the location of sensors is fundamental for the reliability of measurements. In this study, the sensors were transported by the robot, and its mobility was exploited both for taking the measures close to the user and for monitoring them in the whole space. The parameters measured by the sensors were the illuminance $(\mathrm{lx})$, the indoor temperature $\left({ }^{\circ} \mathrm{C}\right)$, the relative humidity $(\%)$, and finally, the sound pressure level $(\mathrm{dB})$. To collect the environmental parameters, we used the following sensors:

- A humidity and temperature sensor provided by the SHT31 Smart Gadget device, which is also endowed with data logging capabilities and Bluetooth Low Energy (BLE) connectivity.

- A light sensor provided by the ISO-Tech ILM350 Digital Lux Meter, which is designed to give light level readings up to 50,000 lx. It also allows light measurements away from the subject area to be collected.

- The microphone of a Huawei smartphone to obtain the sound pressure levels.

The robot, moving close to the user, gives her/him guidelines for positioning sensors in particular locations to take the validation point measurement. For example, the above-mentioned standard EN12464 recommends having $500 \mathrm{~lx}$ on the desk when a user performs a read task. Hence, the robot asks for the user's collaboration in positioning the sensor at a point where (s)he reads most often. Thus, it can take one measurement in a place where permanent sensors are usually not positioned.

Then, to acquire information about the user, the robot applies the POE questionnaire. Such a survey was designed to obtain user's feedback about his/her preferences and sense of well-being related to thermal, visual, and acoustic conditions. For example, some questions were about: (i) the thermal satisfaction (the expected answers were based on the ASHRAE seven point sensation scale [3] ranging from very satisfied to very dissatisfied); (ii) the illuminance conditions (i.e., "Too dark, Ok, Too bright"), and the perception of the noise in the environment.

\subsection{The Lighting Simulation Software}

The evaluation of the environment state depends on the knowledge of a scalar field defining the spatial distribution of a parameter. The correct knowledge would require a significant number of sensors. However, this solution is usually expensive. Moreover, it does not give a good description of the field because some points are difficult to equip with measurement sensors. In a previous work [20], a solution based on unique sensor moved to different points was revealed to be appropriate only for parameters affected by low variations. Since illuminance exhibits a greater gradient, a different approach was devised.

In this work, we improved the knowledge by employing a suitable simulation software used to reproduce the illuminance inside an environment where, due to the solar radiation in the presence of clouds or when there are artificial sources, significant variation at short distances could occur. The use of suitable software reproduces the field inside the environment with a reduced amount of information. It represents an inexpensive trade-off since it requires only a model of the environment under study and an initial validation to assure a proper position of the measurement point. We used the lighting simulation software Dialux Evo [46] to perform a set of simulations of the office selected as a case study. Hence, a single measurement station equipped with temperature, humidity, and illuminance sensors to be placed at appropriate points with the user's participation aided by the robot was employed. In principle, the illuminance software is self-consistent. It can reproduce the illuminance based on the model of the environment and lighting sources. We decided to validate the simulation model both at design time and at run time. At design time, the model was validated by some experimental points to compensate the errors due to an imprecise knowledge of both the environment (e.g., the presence of furniture or wall paintings) and the light sources (e.g., aging of artificial light). Then, at run-time, the validation was performed through the measurement acquired by the robot during the survey.

\subsection{Workflow of the Explainable POE Approach}

The EPOE approach is conceptually represented by the diagram depicted in Figure 1. As previously mentioned, it was implemented on a humanoid robot, which can elaborate, compare, 
and analyze different kinds of data. These data come from various sources: the survey submitted to the users, the values of the environmental parameters measured by the sensors, the standard opportunely formalized to be robot readable, and the simulation software results.

The process enclosed by the dotted square shown in Figure 1 was performed iteratively for each type of environmental comfort, namely thermal, acoustic, and visual comfort. This process is generically described in the following.

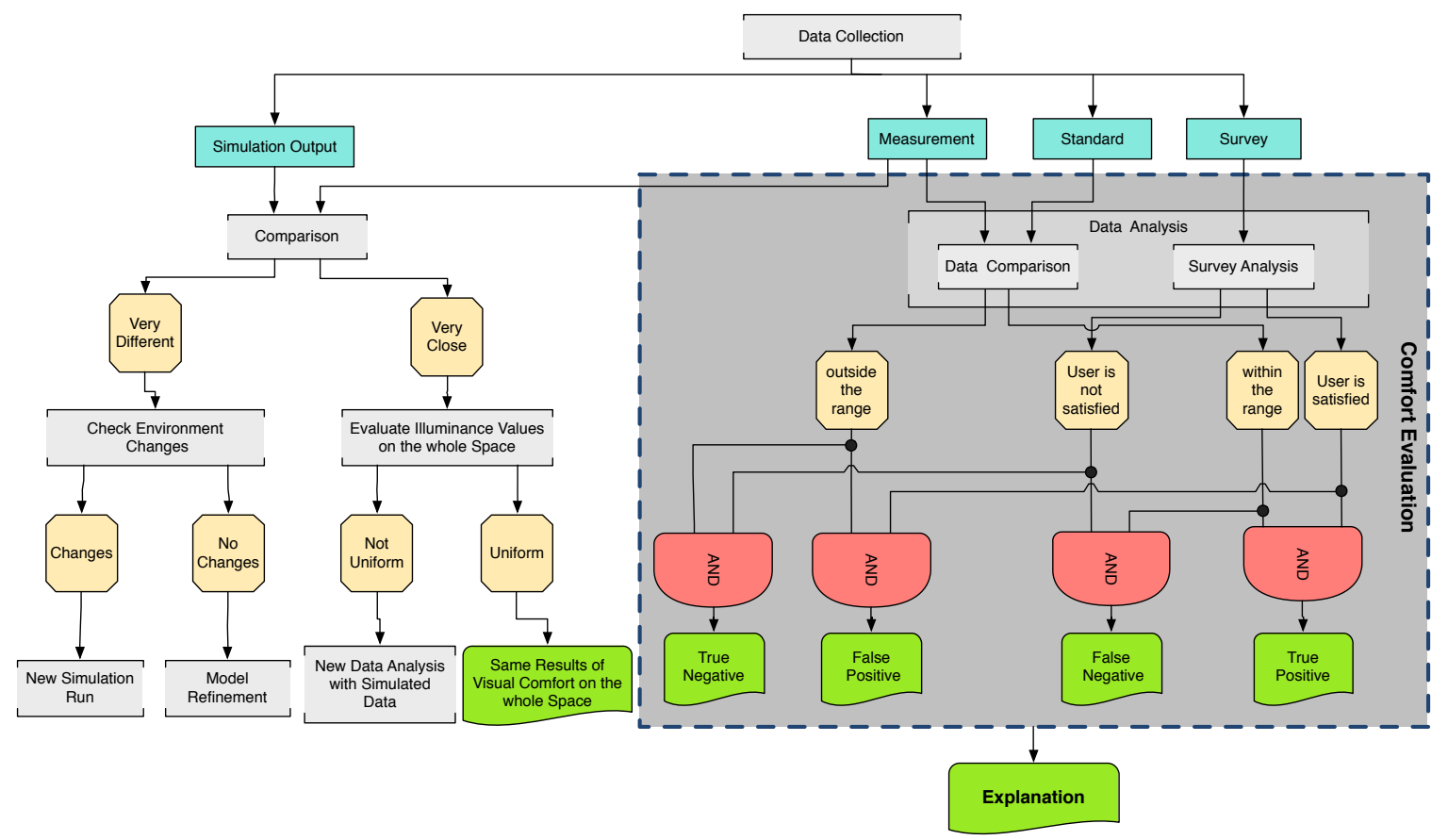

Figure 1. Conceptual flow diagram of the Explainable Post Occupancy Evaluation (EPOE) approach.

The analysis of the data collected by the survey can provide, for each kind of comfort, two outputs according to the user's answer: the user is satisfied or not (see Figure 1). The environmental parameters of the office were compared with the values suggested by the standards to evaluate the compliance. From this analysis, it is possible to know if the measured values are within or outside the range of the suggested values. These last options were compared with the user answers. Hence, four different cases can occur:

- The user feels good, but the values provided by the standard are not achieved. This is classified as a False Positive (FP) result. This implies that the robot produces a report explaining that, despite the user perception, the environmental conditions are not adequate. The robot may suggest some corrections or changes in user habits to improve user comfort, also considering the standards.

- The user does not feel good, and the values provided by the standard are not achieved. This is classified as a True Negative (TN). This implies that the robot produces a report that underlines the violated standard that causes discomfort.

- The user does not feel good, but the values provided by the standard are achieved. This is classified as a False Negative (FN). Furthermore, in this case, the user has to change something to improve the comfort. The robot may underline that some psychological or physiological conditions are the cause of this perception, and also, the robot may give some suggestions about the boundary conditions to be verified.

- The user feels good, and the standards are followed. This is classified as a True Positive (TP). In this case, the robot informs the user that her/his environment is fully compliant with the standard. No further actions are proposed. 
The proposed classification allows for quantifying improvement after the robot intervention.

The second part of the methodology takes into account the output of the lighting simulation software in order to detect if the visual comfort is only a local situation or that it is reached in the whole space. Thus, firstly, the data belonging to the experimental point are compared to those obtained by the software at the same point. This step allows us to avoid errors due to some approximation of the model, both the environment and the light sources.

If the simulation is assessed (i.e., the data are very close), the simulation results are used to estimate the light distribution in the whole space. Two cases can occur (see Figure 1). The first one corresponds to the uniformity of the simulated values on the space (meaning that the standard deviation lies within a threshold). As a consequence, we can assume that the result of the visual comfort evaluation obtained by the previous step can be extended to the entire space. The second one occurs when a high variation of simulated data is noticed. In this case, a new analysis of visual comfort is performed based on the simulated data. This analysis may describe a situation characterized by different visual comfort conditions throughout the space.

Otherwise, if the comparison shows that the simulated data are very different from the validation point, it is necessary to check the cause of the problem. The model's parameters are not precise or the environmental conditions changed during the range of time from the first measurement and the simulation. Thus, the robot firstly asks the user if the environmental conditions have been changed in the last few minutes (e.g., the presence of new clouds, the actions of opening or closing the shade systems). If the environmental conditions are changed, a new simulation run is performed with the new inputs. Conversely, a model refinement is required.

The final result of the process is an explanation about the environmental conditions of the user along with some suggestions if this is the case. For example, the robot may suggest the area of the room where the best visual comfort could be achieved. In the following, a detailed case study is proposed to illustrate the proposed approach.

\section{Case Study}

An office located in the National Research Council building in Palermo ( $38^{\circ} 09^{\prime} 55.4^{\prime \prime} \mathrm{N}$, $13^{\circ} 18^{\prime} 34.9^{\prime \prime} \mathrm{E}$ ) was considered as a case study to test the proposed approach to improve the comfort conditions. Figure 2 shows the Google view of the building. The choice of the office was based on the feedback of some workers unsatisfied with their environmental conditions. The office is generally occupied by two workers on different days and different hours of the day. For this reason, in this study, only one worker was selected to conduct the questionnaire. The room selected as a case study (Figure 3) is characterized by an area of $21.41 \mathrm{~m}^{2}(6.15 \times 3.50 \mathrm{~m})$. It includes some furniture: a table with four workstations, two book cabinets close to the door, and a small cabinet on a wall. On the shorter wall, there is a window $1 \mathrm{~m}$ from the floor, and it is $2.3 \mathrm{~m}$ large.

The real image of the office under study is shown in Figure 4. The large window is equipped with white drapes, whose transmission factor is equal to 0.70 . It is exposed to $285^{\circ}$ west. The office is equipped with: a big painted wooden desk ( $r=0.60$ where $r$ is the reflection coefficient) with a small portion painted black located in the middle of the room; two painted wood cabinets $(r=0.60)$ equipped with glass doors $(r=0.70)$, located almost symmetrically with respect to the door; a small painted wood cabinet $(r=0.60)$ at the end of the opposite wall; and four chairs made of blue and black material $(r=0.20)$. The door of the room is made of steel painted blue $(r=0.20)$. The work-plane of the participant for the test is equipped with two desktop PCs with three big monitors. Moreover, usually, a laptop is positioned under the first monitor. 


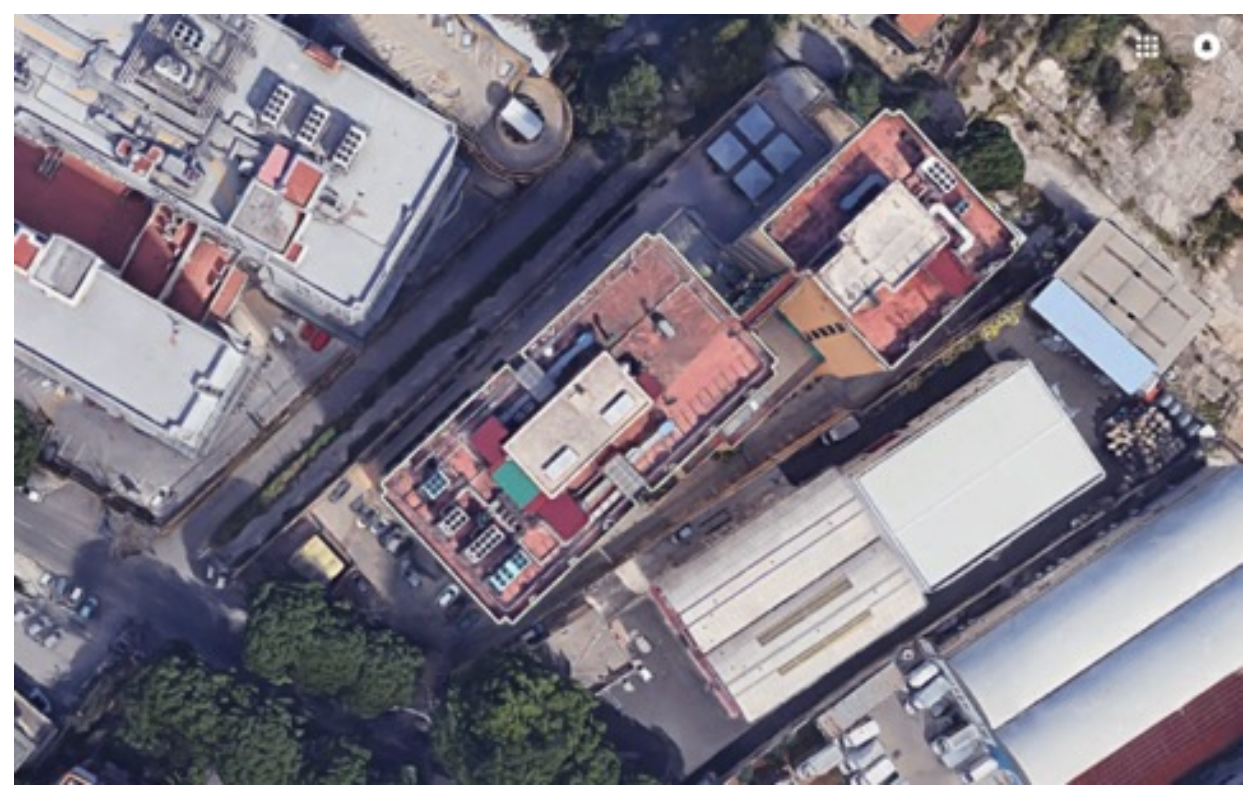

Figure 2. Google view of the National Research Council building in Palermo.

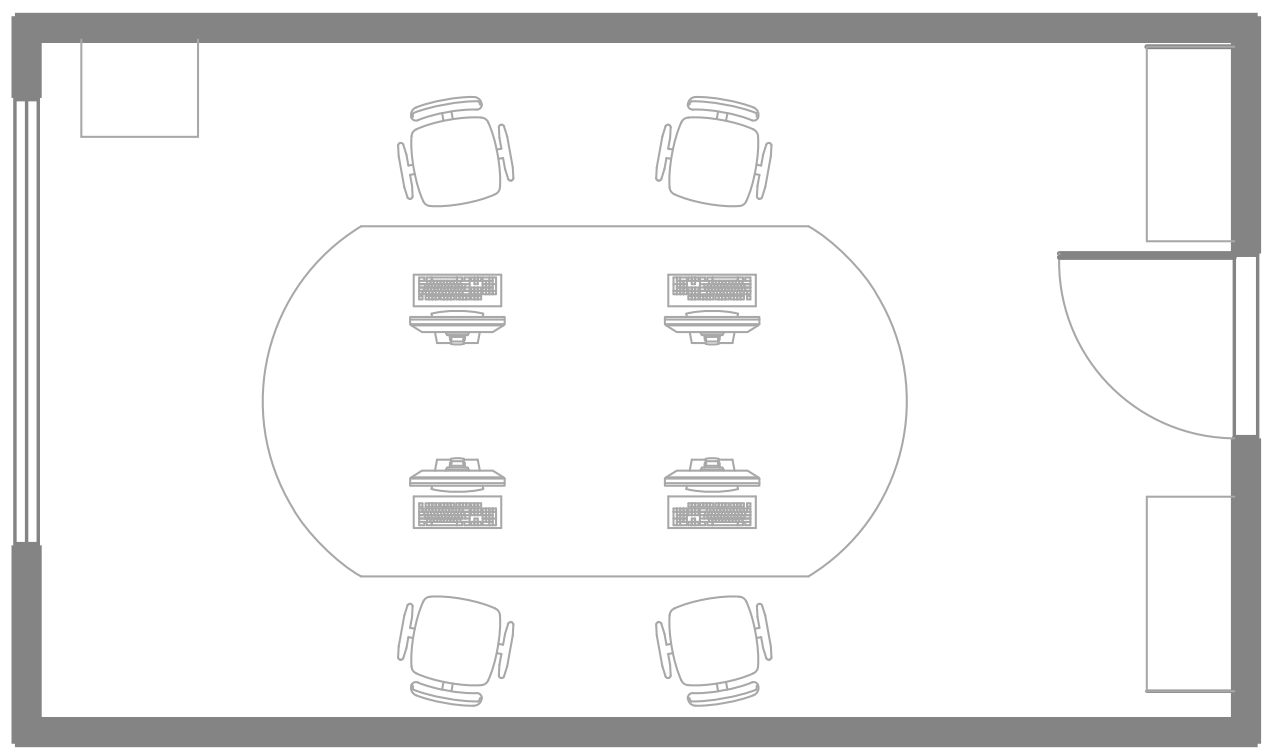

Figure 3. Floor plan of the room under study.

As already mentioned, in this study, four different environmental parameters are taken into consideration: sound level, temperature, humidity, and illuminance. To check the distribution of the measures in the office, a measurement campaign was carried out at different points. Notably, as concerns the illuminance, the measures were retrieved on a regular grid of points placed on the work-plane as a one-off condition to verify the implementation of the furniture and lighting sources. It should be remarked that in the operating conditions, a single validation point was used.

Regarding the illuminance results, in general, it is noted that the room shows some critical aspects tied to the position and exposition of the window. Indeed, the distribution of the illuminance exhibited high variations among the measurement points. Conversely, temperature and humidity showed more homogeneous values. As was confirmed by the standard deviation of the illuminance (see Table 4), there was a relevant difference between the minimum and the maximum value of the illuminance measures. On the contrary, the standard deviation of the temperature was 0.6 , and the standard deviation of the humidity was 1.2. The possibility to gather values close to the user may outperform the limitations of the traditional position of the instrument. Looking at the measures of the lighting 
contribution in Table 4, it is possible to see that the values suggested by the standard EN12464 were not achieved on the whole work-plane. Such measurements refer only to the contribution of daylight. It was noted that artificial light did not improve the illuminance during the daylight hours.

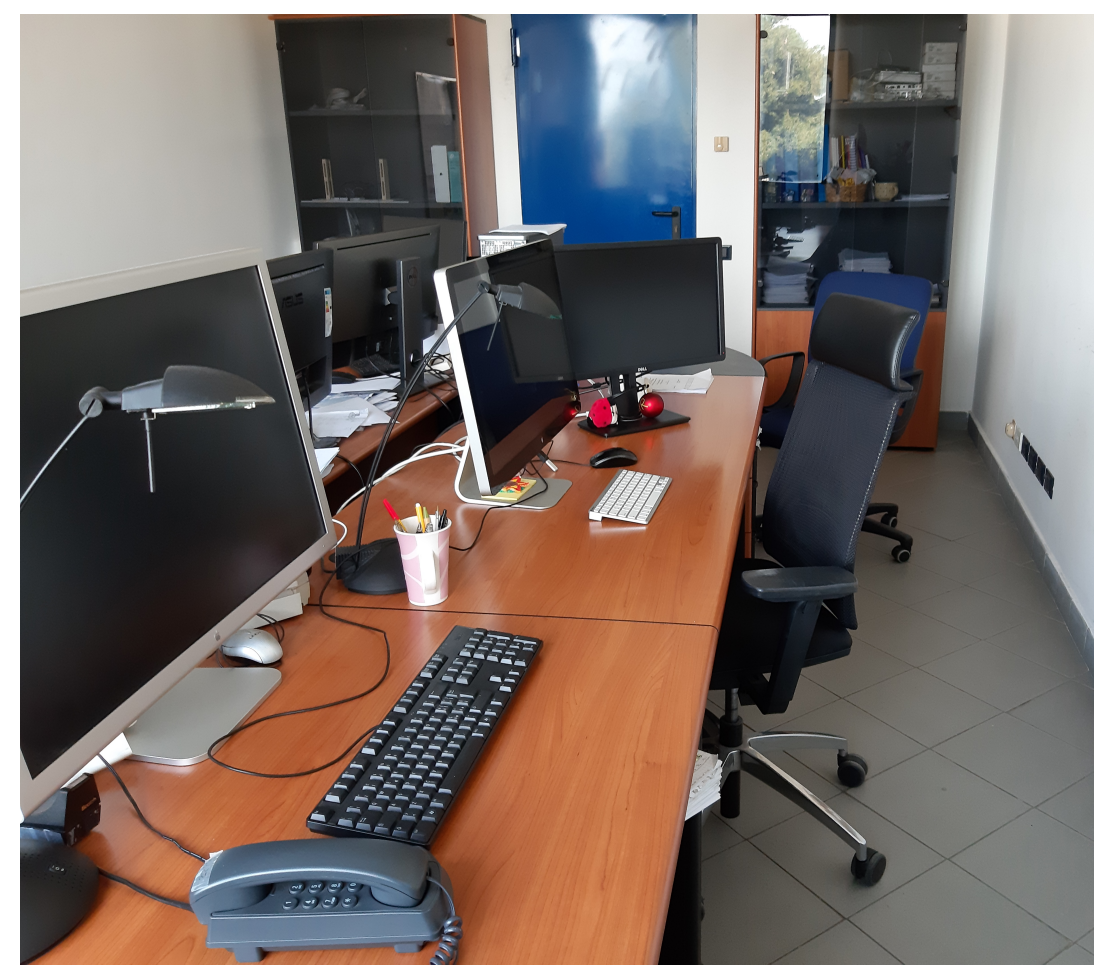

Figure 4. Photograph of the office under study.

Table 4. Table with the maximum and minimum values.

\begin{tabular}{cccc}
\hline & Illuminance [1x] & Temperature $\left[{ }^{\circ} \mathrm{C}\right]$ & Relative Humidity [\%] \\
\hline Min & 52 & 22.95 & 40.89 \\
Max & 376 & 25 & 44.48 \\
Mean & 181.1 & 23.73 & 43.35 \\
Dev.Stand & 75.5 & 0.6 & 1.2 \\
\hline
\end{tabular}

\subsection{Software Output Analysis}

The digital model of the office shown in Figure 5 was implemented in the software Dialux Evo. All the optical characteristics of the surfaces of the room were implemented in the model. Furthermore, a maintenance factor of 0.8 was set. To perform the daylight simulation, an hour of a day and the sky conditions (http:/ / www.cie.co.at/publications/cie-standard-overcast-sky-and-clear-sky) were selected. Some simulations were performed at different hours of the day. A calculation surface was positioned at the height of $0.75 \mathrm{~m}$ from the floor (see Figure 6). This comprehends the whole area of the work-plane available for the user. The portion of the desk behind the first monitor (i.e., black semicircle on the right) was not considered due to its irregular form, which resulted in being uncomfortable for the user.

Figure 7 shows the isolines of the illuminance values calculated by the simulation software. It is a 2D representation of the values shown in Figure 6. 


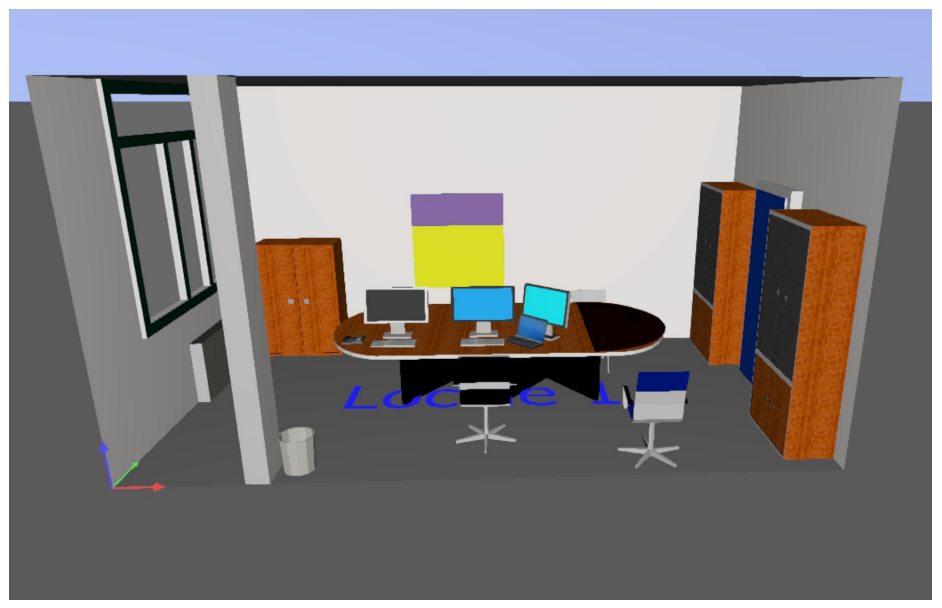

Figure 5. The 3D model of the office under study.

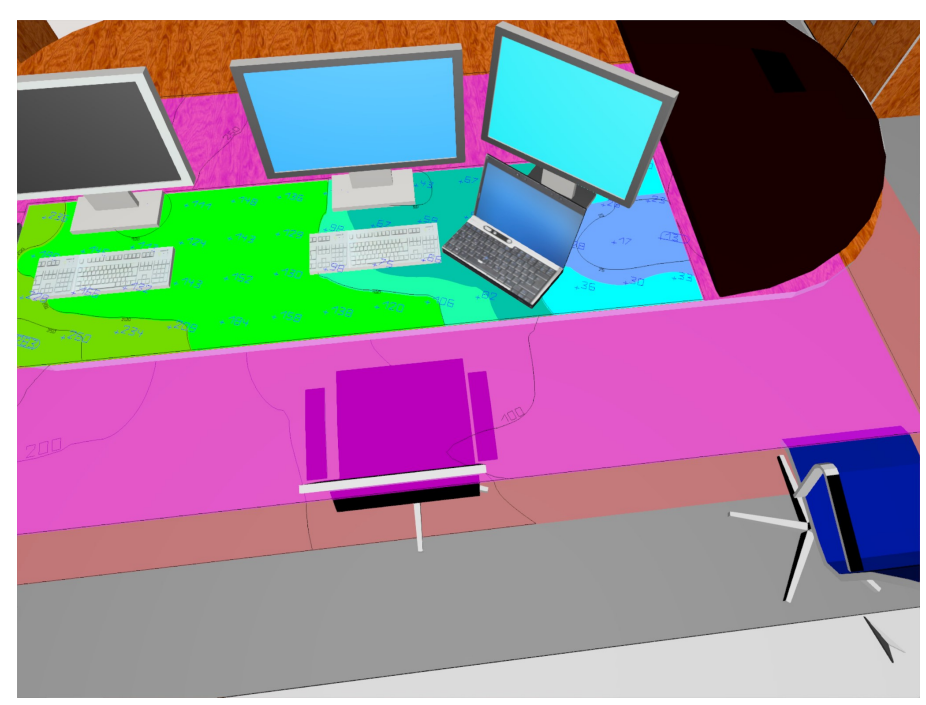

Figure 6. Calculation surface on the work-plane.

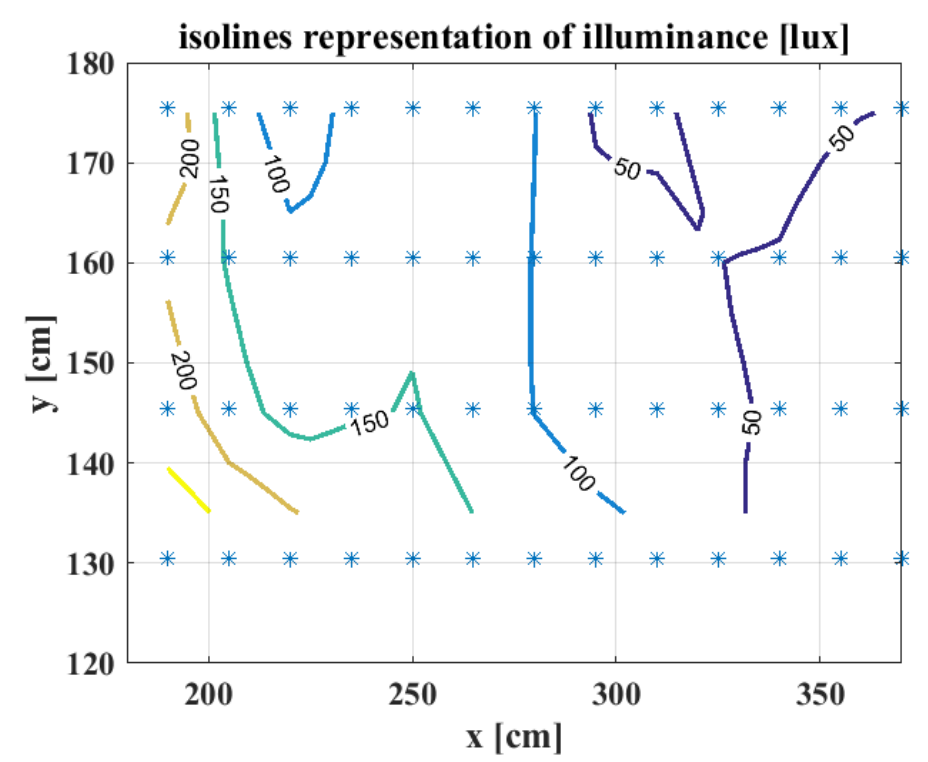

Figure 7. Simulated illuminance values on the work-plane. 
As can be noticed, the obtained values decreased significantly from the points near the window towards those near the door (i.e., far from the window). This is more evident considering the 3D representation of the illuminance in Figure 8, where a variation in the $\mathbf{y}$ coordinate can be appreciated. This situation always occurs during the day since it is tied to the position of the window. Moreover, during the day, the illuminance values compliant with the technical standard EN12464 are only rarely achieved at some points.

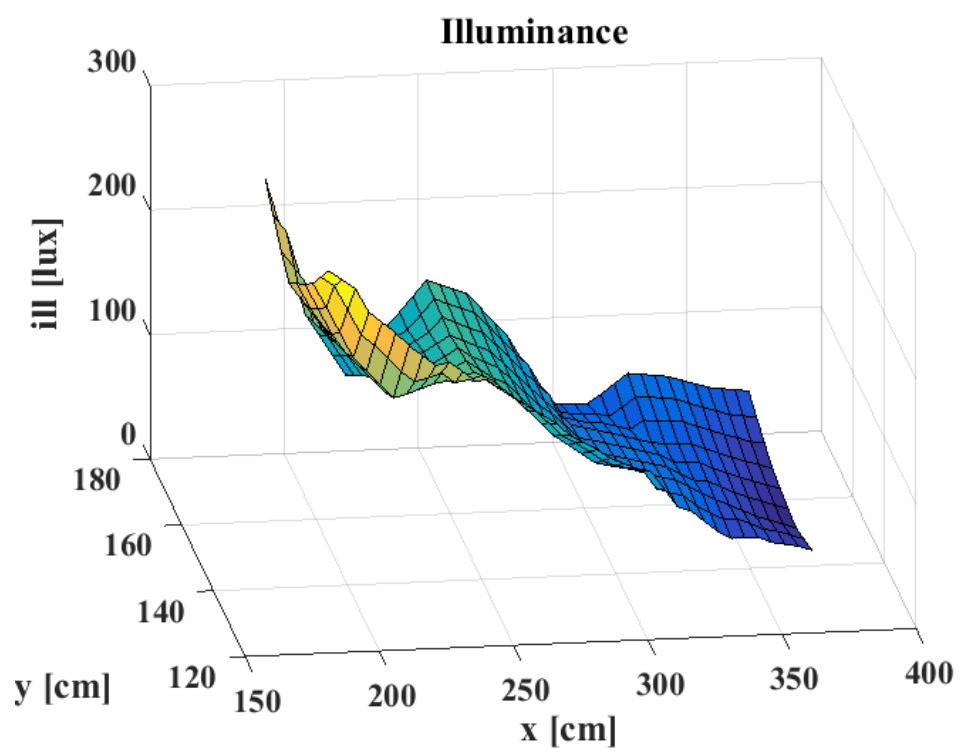

Figure 8. The 3D representation of the illuminance values on the work-plane.

Some simulations were carried out considering only the natural lighting and the simulation considering both natural and artificial light. It is noted that artificial light did not improve the illuminance during the hour of the daylight.

In the diagrams depicted in Figure 9, the simulated illuminance values are compared with some experimental values to assess the accuracy of the results. They show a variation throughout space and time. In particular, they refer to the values of the illuminance (simulated and real ones) of the office taken on 4 December 2019. Both simulations and the acquisition of the real data were performed with the artificial light off, the door closed, and the window drapes open. The first and the second data acquisition were performed at 11:00 a.m. and 12:30 a.m.when the sky was clear. Instead, during the third acquisition at 2:30 p.m., the sky was cloudy. The simulation was run by setting the same time when the measurements were taken and the same sky conditions.

The three diagrams on the top refer to a fixed time and y coordinate of the work-plane, whereas the $x$ coordinate ranges from 170 to $360 \mathrm{~cm}$. Taking into account that the origin of the reference system corresponds to the corner on the bottom left, as shown in Figure 5, these values span the whole work-plane. Conversely, the three diagrams on the bottom of Figure 9 were retrieved by fixing a point on the work-plane, varying the time from 11:00 a.m. to 2:30 p.m.

As concerns the comparison of the real and simulated values shown in the top diagrams, it can be noticed that a good agreement was maintained until the right edge of the work-plane. In this part, very low values were retrieved, making this part unsuitable throughout the hours of the day. This is confirmed by the bottom diagrams in which the discrepancy remains low at the point at coordinate $(190,135.5)$, and it is slightly higher at the point $(280,135.5)$, while it dramatically increases at the point $(355,135.5)$ at the right edge of the work-plane. In general, the difference between measured and simulated values can be considered acceptable, confirming that, in operating conditions, a single validation point is sufficient to assess the reliability of the simulation. 
It should be remarked that this comparison was performed at more points to show that the simulation software was quite accurate both in space and time, confirming that for practical use, a unique measurement point can be considered. Besides, a noticeable error was obtained only at points on the right edge of work-plane that were not exploited.
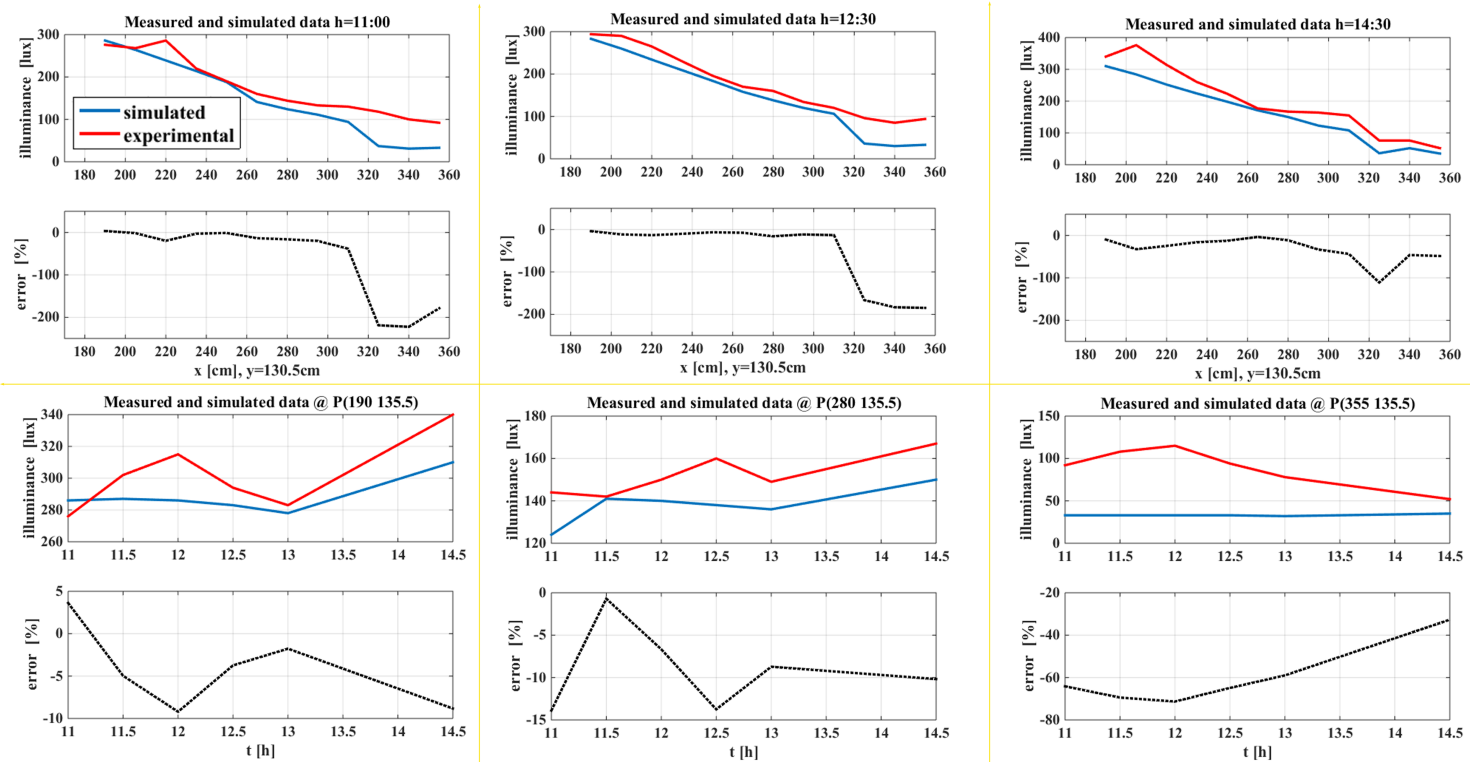

Figure 9. Representation of simulated (blue lines) and real (red lines) illuminance values versus space and time and the related percent error (dotted lines).

\subsection{Survey Session and Results}

In this section, a detailed description of the interaction between the user and the humanoid robot is presented. It can be considered as a novelty of the proposed approach aiming to establish a dialogue in which the user gives fruitful information to the robot to perform its analysis, and (s)he receives from the robot dedicated explanations about her/his condition and how to improve it when necessary. This is the crucial step in which POE becomes EPOE.

In this study, the experimentation was conducted by using a Nao robot. The Nao robot belongs to the class of humanoid robots (see Figure 10), and it is an autonomous and programmable robot developed by the French company Aldebaran Robotics to provide an open and accessible, high-performance robot platform for both researchers and the general public. The Nao robot is endowed with multitude of sensors, motors, and software handled by an ad-hoc operating system. It has several features to demonstrate natural interactions with humans [47]. The most important feature of the Nao robot is the possibility to be personalized utilizing Choreographe [47]. This is a user-friendly programming suite that allows us to control the robot, create behaviors, and access the data acquired by the sensors. It also allows for testing new behaviors on a simulated robot.

During the session of the POE survey, the robot recognized the user, and it moved towards her/him. Then, it provided her/him guidelines for placing the external sensors in appropriate locations to take the right measurements. After that, the robot applied the POE questionnaire to the user. Finally, by the analysis of the data obtained from the survey and the sensors, it provided the user with a report of her/his working environment quality, giving some recommendations. The interaction between the robot and the user took about 10 minutes. The whole dialogue between the user and the robot during the monitoring session at 12:30 is reported in Appendix A. 


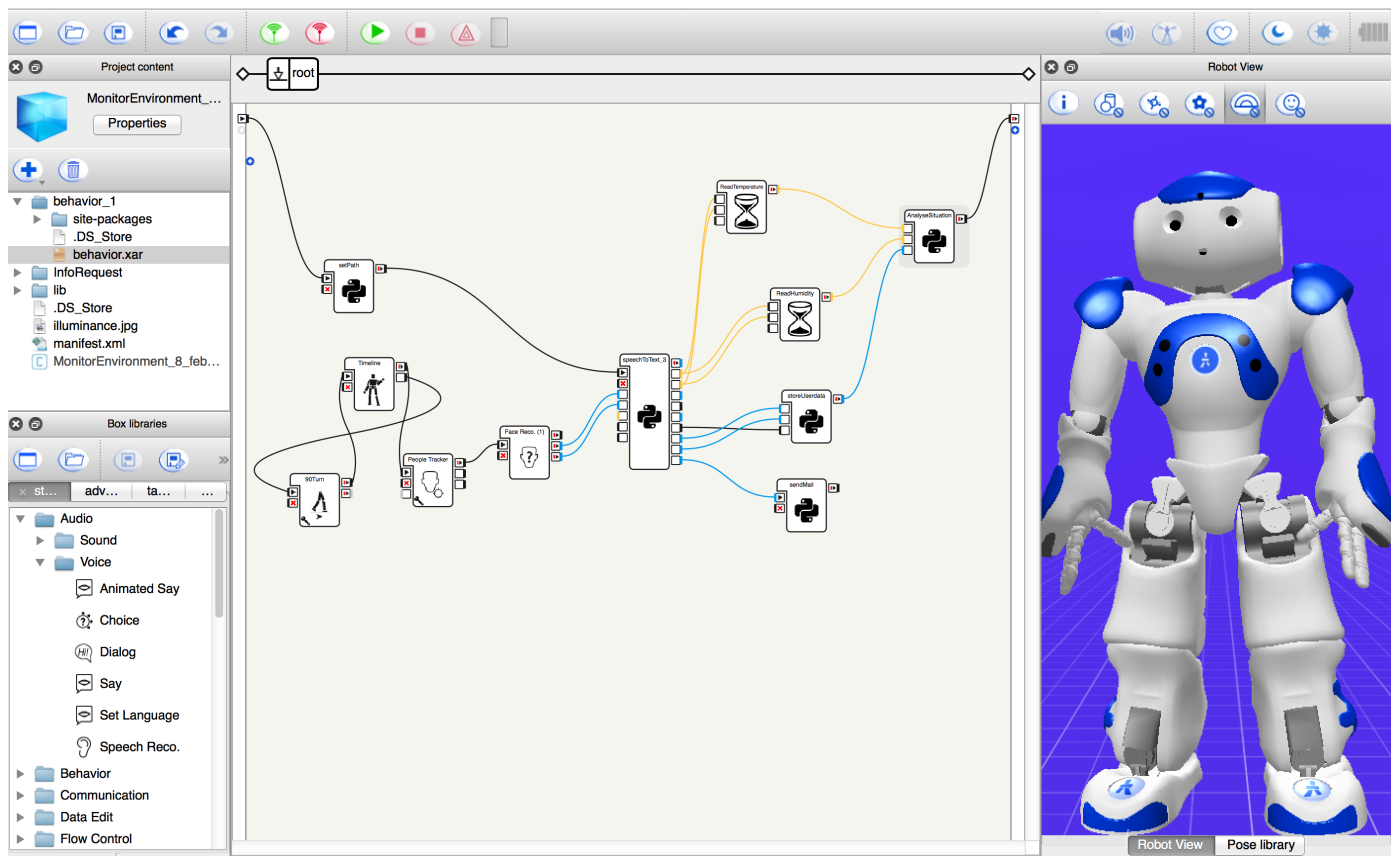

Figure 10. The robot Nao and the Choreographe environment.

During this session, the user placed the illuminance sensor at the point of coordinate $(280,135.5)$. From the survey, the robot acquired different information from the user. The most important information for the analysis was the following:

- The user perceives a warm working environment.

- She prefers feels a bit cooler.

- She did not like the illuminance conditions, perceiving a too dark environment.

- She prefers a warmer light.

- She considers her environment noiseless.

In addition, the robot gathered through the sensors the following values of the environmental parameters:

- Illuminance level of $160 \mathrm{~lx}$.

- $\quad$ Sound pressure level of $35 \mathrm{~dB}$.

- Temperature of $22^{\circ} \mathrm{C}$.

- Relative humidity of $43 \%$.

Thus, analyzing such data, the robot detected the following situations:

- Thermal comfort: false negative. The environment conformed to the standard of thermal comfort. The current temperature was in the range of the value recommended by the standard in the winter months. Nevertheless, the user felt warm; she would like to have more manual control of the temperature.

- Visual comfort: true negative. The environment did not conform to the standard of visual comfort. The user did not like the illuminance, and she preferred a warmer color temperature.

- Acoustic comfort: true positive. Finally, the environment conformed to the standard of acoustic comfort. The occupant perceived a quiet environment.

Moreover, as can be noted from the simulated values reported in Figure 7, there were no locations in which the standard values of the illuminance were satisfied. For this reason, the robot did not recommend to move to a better work position. Conversely, when among the simulated values, one or more points compliant with the standard appeared, the robot may suggest that the user vary her work position by exploiting the better natural light in the office. 
From the user interview, it can be noted that two situations needed a correction. Hence, the robot recommended the user to decrease the temperature up to the min value of the standard, and it also suggested to verify if she was heavily dressed. Moreover, it suggested using a table lamp with warm lights, as she preferred, and to verify if it was a more pleasant situation.

The user, according to the robot suggestions, tried to follow them to improve her comfort opportunely. In particular, she placed a table lamp with warm light (i.e., $3000 \mathrm{~K}$ ) on her work-plane, as is possible to see from the real figure of the room in Figure 4. As concerns her perception of the temperature, she tried to set a lower operating point temperature of the fan-cooler. Thus, a new POE questionnaire was performed with the user after a suitable time interval to evaluate if the corrections effectively improved the situation. The robot detected the following new situations. Old results are reported near the most recent (old result $\rightarrow>$ new result).

- $\quad$ True negative $\rightarrow>$ true positive. The environment complied with the standard of visual comfort. The user perceived a better visual situation.

- $\quad$ False negative $\rightarrow$ false negative. The environment conformed to the standard of thermal comfort. The current temperature was in the range of the value recommended by the standard during the winter months. Nevertheless, the user continued to feel warm.

- True positive. Finally, the environment complied with the standard of acoustic comfort. The user perceived a quiet environment.

The introduction of a table lamp effectively improved the visual comfort of the user, although this situation was obtained only close to the user's working area. However, a report recommending an improvement of the artificial lighting system was sent to the maintenance manager. Conversely, the situation of the thermal comfort remained unsolved. A further investigation put in evidence that the thermostatic control was out of operation.

\subsection{Discussion}

As we stated previously, the significant contribution of this paper is a new methodological approach based on a humanoid robot along with a simulation lightning software for improving indoor comfort conditions and user awareness of his/her environment and cooperation in the control process, leading to the new concept of explainable POE. Even if a measurement campaign is out of the scope of the paper (it will be performed in future work), the verification of the method on a case study allows highlighting the main strengths. The most important advantage to using a humanoid robot is to attract the attention of the users about their real environmental situation and provide them with personalized suggestions to improve their well-being. This is coherent with the literature; indeed (as was found in [26]), often, users' attention is completely absorbed by the task he/she is performing, making him/her unaware of the discomfort situation. Moreover, humans find it more pleasant to collaborate with robots that are socially competent and show human traits. Additionally, users are more inclined to follow recommendations provided by a physical anthropomorphic device than other kinds of systems. In addition, the use of a humanoid robot proved to be effective due to its mobility. Indeed, it can collect environmental data at several points of the environment without a previously installed set of sensors, which could be an expensive solution, especially when it needs to be installed in existing old buildings. The use of a robot becomes an inexpensive solution considering that the sensors represent a fixed installation that should be repeated in every environment to be monitored. The robot, on the other hand, can move from one environment to another carrying an inexpensive and small system containing a sensor for each type of parameter to be measured and can use its wireless interface system to communicate information. Hence, to control many environments, such as the dozens of offices of the National Research Council of Palermo, the use of a robot can become a more affordable solution, also considering that the same robot can be used for other applications when it is not used for monitoring. For the above-mentioned reasons, the proposed approach is less invasive compared with monitoring with a fixed sensors array. Besides, a limitation of classical 
approaches is the difficulty to place sensors in particular locations, such as the center of the desk where the illuminance has to be measured. Our work is based on human-robot collaboration cooperation in positioning the sensor at the measuring point. In this way, the user, for example, can take the measurement where (s)he reads most often; this type of performance cannot be achieved with fixed sensors. By endowing the robot with sensors, these can be easily substituted or increased, if necessary, to improve the measurement. Finally, when more than one occupant occupies a room, the preferences of the occupants can be considered by the robot and used to propose an eventual trade-off in the case that some occupants' preferences are different.

Along with the robot, the proposed methodological approach takes advantage of the complementary employment of simulation software that retrieves the spatial distribution of an environmental parameter. In general, the use of such software was revealed to be suitable to improve the knowledge of the parameters with a wide range variations, whereas for quantities with small spatial and temporal variations, the single sensor with which the robot is equipped is sufficient.

Conversely, a drawback in using a humanoid robot is that the space in which it has to operate needs to be robot-friendly, namely without relevant obstacles, such as steps, that can interfere with the robot's mobility. The second drawback is related to the Dialux simulation model updating, which in the current implementation of the approach requires human intervention; however, the model implementation is needed only the first time, then it can be exploited to retrieve the illuminance distribution based on a single measurement point.

\section{Conclusions and Future Work}

In this paper, we introduce the concept of "explainable post occupancy" (EPOE) seeking to make the user aware of his/her well-being status, taking into account both the standards and the user preferences and perceptions. Adopting the EPOE approach concerning the existing proposals in the literature, the users have a better understanding of the environmental comfort situation, thus acquiring more consciousness about their safety and health conditions. This is obtained thanks to the use of a humanoid robot. Indeed, a humanoid social robot is conceived of to reproduce more cues, to show many human characteristics (such as natural language and anthropomorphic physical aspects), and to communicate with humans in ways that resemble interpersonal relationships. Such humanization produces positive effects within human-robot interactions both at the cognitive and the emotional level, thus providing adequate support to people. The EPOE approach is different from the traditional ones in which a conventional automatic control system operates based on the difference between a reference parameter and the value measured by one or more sensors. Based on the well-known result that the illuminance is one of the most significant elements for providing comfort and that it is affected by a high variability both in space and in time, we use a lightning simulation software to reproduce the field inside the environment based on a reduced amount of information. This mitigates the problem of the spatial distribution of the real sensors, as well as reduces their installation costs. The EPOE approach is assessed on a case study allowing us to show also the interaction between the robot and the user, including the explanation given at the end. By this explanation, the user acquires consciousness about his/her real working condition, and (s)he is able to improve it in some cases. Since four different situations, for each considered parameter (i.e., illuminance, temperature, relative humidity, and noise level), are recognized, a new classification is proposed, meaning that (i) the user feels good even if the the environment does not conform to the standard; (ii) the user feels good, and the environment fits with the standard; (iii) the user is not satisfied even if the standard values are achieved; and finally, (iv) the user is not satisfied, and the environment is not compliant with the standard. These situations are respectively classified into the following four categories: false positive, true positive, false negative, and true negative.

The authors believe that their approach could be a good trade-off between the objective classification given by the standard and the subjective perception of the users. 
Finally, regarding the whole comfort evaluation, we are currently working to develop a low cost embedded system endowed with sensors able to acquire air velocity as well for a better evaluation of the thermal comfort and a $\mathrm{CO}_{2}$ sensor to evaluate the air quality within the environment as well.

Author Contributions: All authors contributed equally to the manuscript. All authors have read and agreed to the published version of the manuscript.

Funding: This work was conducted in the framework of the project AMICO-Medical Assistance In COntextual awareness (CUP B46G18000390005). Facilitation marked by the identification code ARS01 0090.

Acknowledgments: The authors are very grateful to National Research Council, Area della Ricerca di Palermo, via Ugo La Malfa 153, Palermo, for the availability of the offices where the investigation was carried out.

Conflicts of Interest: The authors declare no conflict of interest.

\section{Appendix A}

The whole dialogue between the user and the robot during the monitoring session at 12:30 is reported in the following. It is worth noting that during the dialogue, the robot uses a language with some domain specific concepts. However, the robot is able to explain such concepts that require explanations by providing definitions and figures to the user. Moreover, in some cases, we use informal terms that are more comprehensible for users. For example, we use the words "dark" and "bright", although there are scales for brightness (that has a slightly different meaning from the light level). This choice was because such terms are used in everyday language to express the perception of light levels.

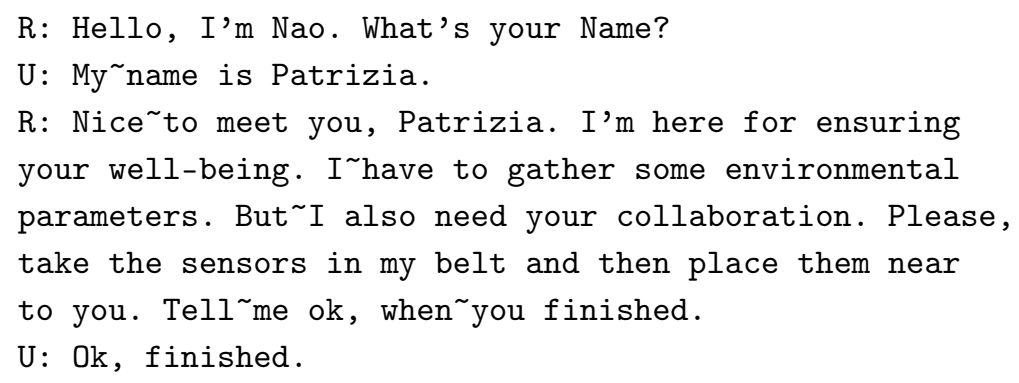

The user placed the illuminance sensor at the point of coordinate $(280,135.5)$. Hereafter, the robot starts the POE questionnaire.

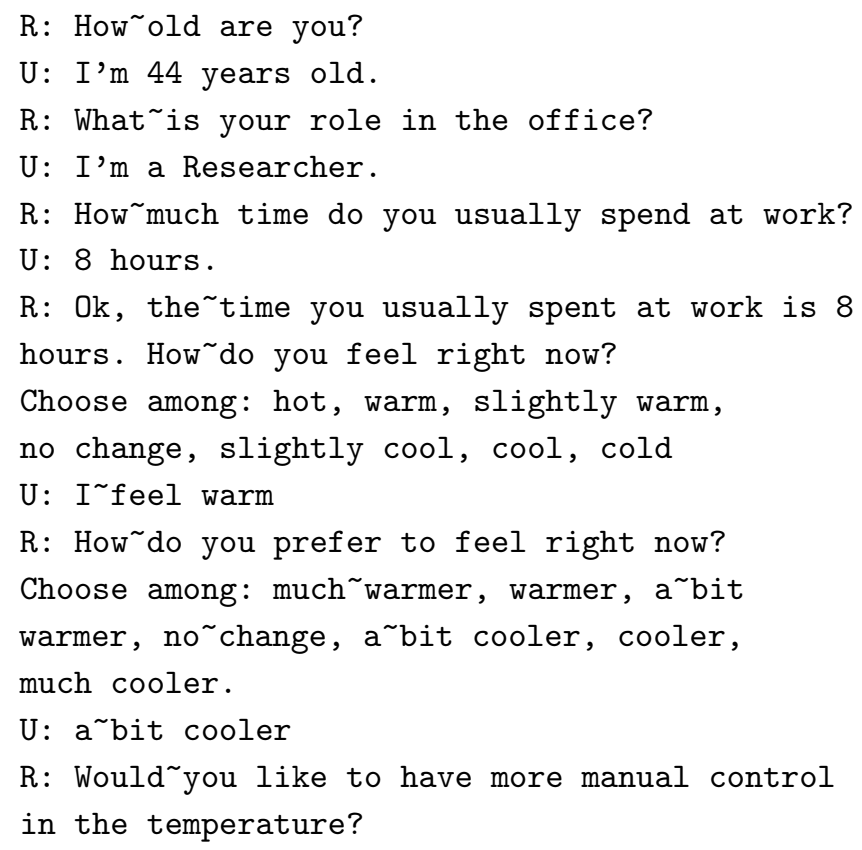




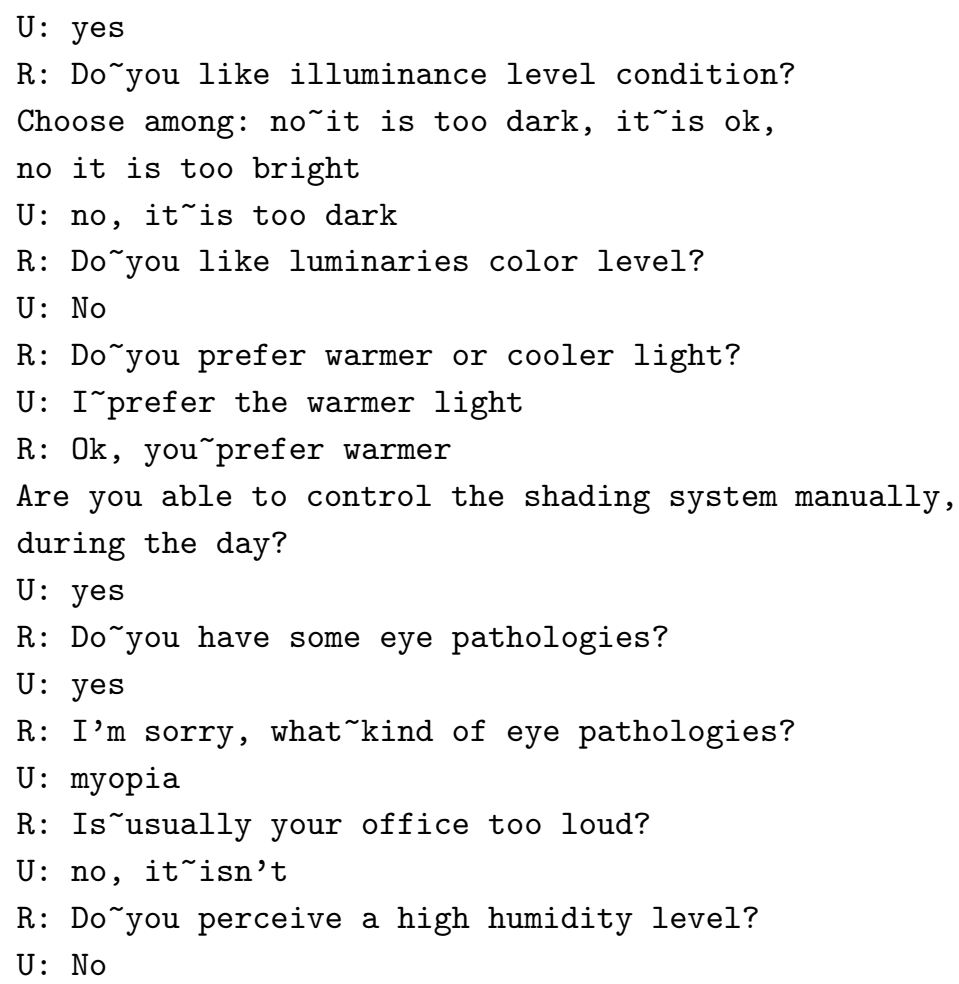

Once the POE survey is finished, the robot acquires from the user illuminance and sound level that the user reads from the sensors placed on her desk.

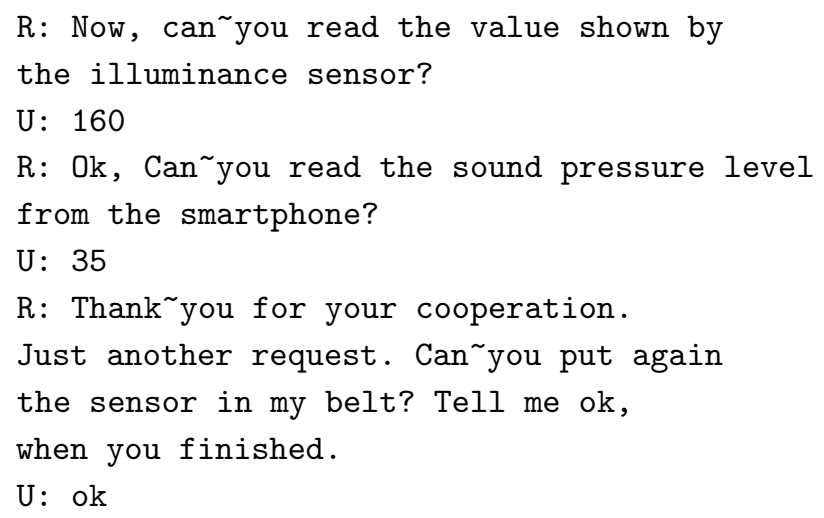

In the meanwhile, the robot has also acquired data coming from the Smart Gadget device about temperature and relative humidity, and it is elaborating the results.

Thus, analyzing the answers of the user and the environmental measurements, the robot detects the following situations:

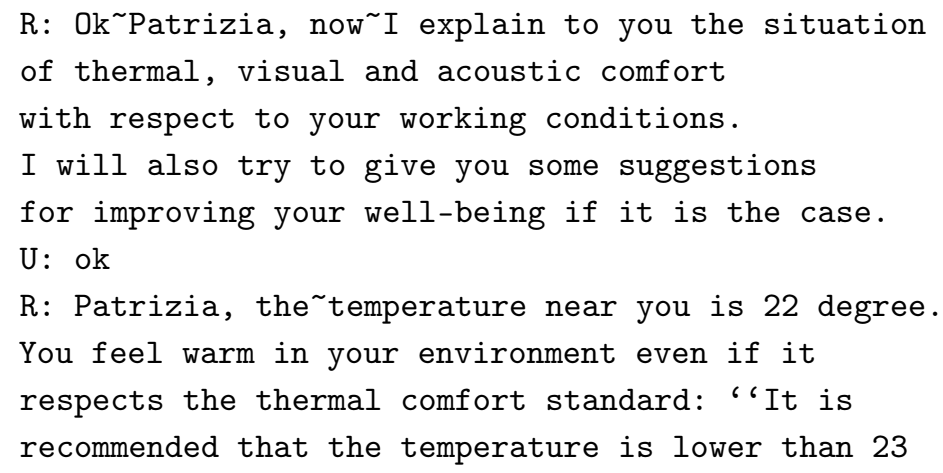


degree and greater than 20 degree if the humidity ranges between $30 \%$ and $60 \%$ if the environment

is a job area, in the winter season.",

I suggest you to decrease the temperature up to the min value of the standard and to verify if you are heavy dressed. Tell me repeat or next for going on.

$\mathrm{U}$ : Ok, next

R: Patrizia, your current work-plane illuminance is 160 .

You perceive bad illuminance because your environment is not compliant with the recommendation: "It is recommended that the illuminance on the work-plane is at least $500 \mathrm{~lx}$ if the environment is a job area.', . Unfortunately, there are no better illuminated locations on your work-plane where you can move. I suggest you to increase the brightness of your workplane surface. Because you prefer a warmer color temperature, I also suggest you to use a table lamp with warm lights to verify if it is a more pleasant situation for your eyes. Tell me repeat or next for going on.

$\mathrm{U}:$ Ok, next

R: Finally, Patrizia your current environment respects the acoustic comfort standard.

I hope to be useful to you. Thank you, bye-bye. $\mathrm{U}$ : Bye.

Hence, the robot explains the situation to the user. In the following, the rest of the dialogue with Patrizia.

R: Ok Patrizia, now I explain to you the situation of thermal, visual and acoustic comfort with respect to your working conditions.

I will also try to give you some suggestions

for improving your well-being if it is the case.

$\mathrm{U}$ : ok

R: Patrizia, the temperature near you is 22 degree.

You feel warm in your environment even if it

respects the thermal comfort standard: "It is

recommended that the temperature is lower than 23

degree and greater than 20 degree if the humidity

ranges between $30 \%$ and $60 \%$ if the environment

is a job area, in the winter season."

I suggest you to decrease the temperature up to the min

value of the standard and to verify if you are heavy

dressed. Tell me repeat or next for going on.

$\mathrm{U}:$ Ok, next

R: Patrizia, your current work-plane illuminance is 160 .

You perceive bad illuminance because your environment is not compliant with the recommendation: "It is recommended that the illuminance on the work-plane is at least $500 \mathrm{~lx}$ if the environment is a job area.', 


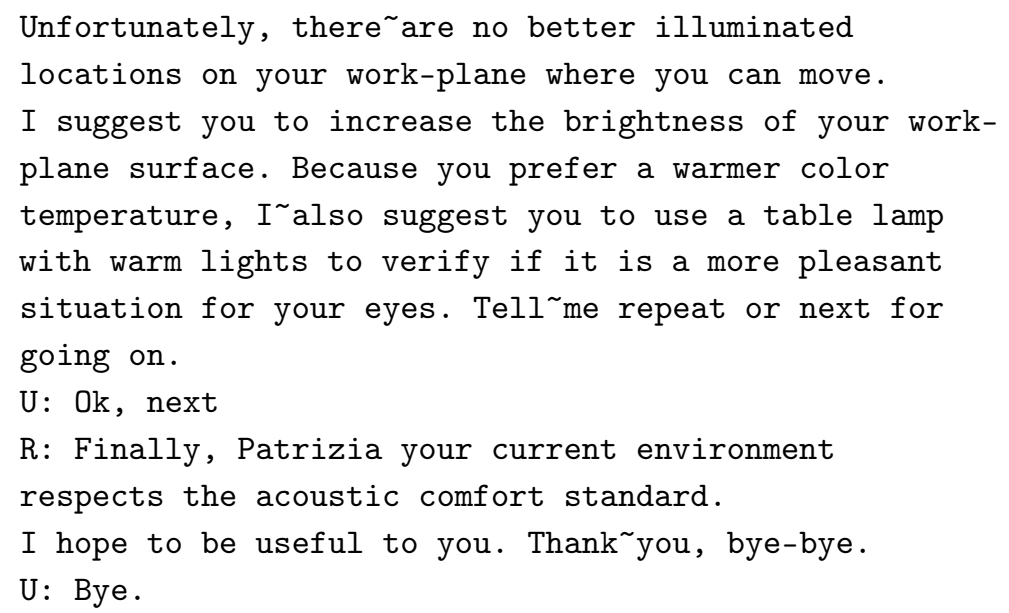

\section{References}

1. Comité Européen de Normalisation. BS EN 15251:2008. Indoor Environmental Input Parameters for Design and Assessment of Energy Performance of Buildings Addressing Indoor Air Quality, Thermal Environment, Lighting and Acoustics; Comite Europeen de Normalisation: Rome, Italy, 2008; Volume 14.

2. ISO. ISO 7730: Ergonomics of the thermal environment-Analytical determination and interpretation of thermal comfort using calculation of the PMV and PPD indices and local thermal comfort criteria. Management 2005, 3, e615.

3. Standard Ashrae. Standard 55-2017 Thermal Environmental Conditions for Human Occupancy; Ashrae: Atlanta, GA, USA, 2017.

4. ISO. Lighting for Work Places Part 1: Indoor (ISO: 8995-1: 2002 E); International Commission on Illumination: Vienna, Austria, 2002.

5. Choi, J.H.; Lee, K. Investigation of the feasibility of POE methodology for a modern commercial office building. Build. Environ. 2018, 143, 591-604. [CrossRef]

6. Pastore, L.; Andersen, M. Building energy certification versus user satisfaction with the indoor environment: Findings from a multi-site post-occupancy evaluation (POE) in Switzerland. Build. Environ. 2019, 150, 60-74. [CrossRef]

7. Kim, J.; de Dear, R.; Candido, C.; Zhang, H.; Arens, E. Gender differences in office occupant perception of indoor environmental quality (IEQ). Build. Environ. 2013, 70, 245-256. [CrossRef]

8. Choi, J.H.; Moon, J. Impacts of human and spatial factors on user satisfaction in office environments. Build. Environ. 2017, 114, 23-35. [CrossRef]

9. Göçer, Ö.; Göçer, K.; Başol, A.M.; Kıraç, M.F.; Özbil, A.; Bakovic, M.; Siddiqui, F.P.; Özcan, B. Introduction of a spatio-temporal mapping based POE method for outdoor spaces: Suburban university campus as a case study. Build. Environ. 2018, 145, 125-139. [CrossRef]

10. Li, P.; Froese, T.M.; Brager, G. Post-occupancy evaluation: State-of-the-art analysis and state-of-the-practice review. Build. Environ. 2018, 133, 187-202. [CrossRef]

11. Yu, X.; Liu, L.; Wu, X.; Wu, X.; Wang, Z.; Liu, Q.; Shi, G. On a Post-occupancy Evaluation Study of Effects of Occupant Behavior on Indoor Environment Quality in College Buildings in Chongqing. Procedia Eng. 2017, 205, 623-627. [CrossRef]

12. Bonomolo, M.; Beccali, M.; Brano, V.L.; Zizzo, G. A set of indices to assess the real performance of daylight-linked control systems. Energy Build. 2017, 149, 235-245. [CrossRef]

13. Bellia, L.; Fragliasso, F.; Pedace, A. Lighting control systems: factors affecting energy savings' evaluation. Energy Procedia 2015, 78, 2645-2650. [CrossRef]

14. Bellia, L.; Fragliasso, F. Automated daylight-linked control systems performance with illuminance sensors for side-lit offices in the Mediterranean area. Autom. Constr. 2019, 100, 145-162. [CrossRef]

15. Gao, Y.; Cheng, Y.; Zhang, H.; Zou, N. Dynamic illuminance measurement and control used for smart lighting with LED. Measurement 2019, 139, 380-386. [CrossRef] 
16. Alzoubi, H.; Bataineh, R.F. Pre-versus post-occupancy evaluation of daylight quality in hospitals. Build. Environ. 2010, 45, 2652-2665. [CrossRef]

17. EN 12464-1:2011. Light and Lighting_Lighting of Work Places_Part 1: Indoor Work Places; Central Bureau of the CIE: Vienna, Austria, 2011.

18. Kallio, J.; Vildjiounaite, E.; Koivusaari, J.; Räsänen, P.; Similä, H.; Kyllönen, V.; Muuraiskangas, S.; Ronkainen, J.; Rehu, J.; Vehmas, K. Assessment of perceived indoor environmental quality, stress and productivity based on environmental sensor data and personality categorization. Build. Environ. 2020, 175, 106787. [CrossRef]

19. Tang, H.; Ding, Y.; Singer, B. Interactions and comprehensive effect of indoor environmental quality factors on occupant satisfaction. Build. Environ. 2020, 167, 106462. [CrossRef]

20. Gao, Y.; Lin, Y.; Sun, Y. A wireless sensor network based on the novel concept of an I-matrix to achieve high-precision lighting control. Build. Environ. 2013, 70, 223-231. [CrossRef]

21. Huang, Y.H.; Robertson, M.M.; Chang, K.I. The role of environmental control on environmental satisfaction, communication, and psychological stress: effects of office ergonomics training. Environ. Behav. 2004, 36, 617-637. [CrossRef]

22. Lee, S.Y.; Brand, J.L. Effects of control over office workspace on perceptions of the work environment and work outcomes. J. Environ. Psychol. 2005, 25, 323-333. [CrossRef]

23. Sakellaris, I.; Saraga, D.; Mandin, C.; de Kluizenaar, Y.; Fossati, S.; Spinazzè, A.; Cattaneo, A.; Szigeti, T.; Mihucz, V.; de Oliveira Fernandes, E.; et al. Personal control of the indoor environment in offices: Relations with building characteristics, influence on occupant perception and reported symptoms related to the building-The officair project. Appl. Sci. 2019, 9, 3227. [CrossRef]

24. Li, D.H.; Lou, S. Review of solar irradiance and daylight illuminance modeling and sky classification. Renew. Energy 2018, 126, 445-453. [CrossRef]

25. Yoon, Y.; Moon, J.W.; Kim, S. Development of annual daylight simulation algorithms for prediction of indoor daylight illuminance. Energy Build. 2016, 118, 1-17. [CrossRef]

26. Ribino, P.; Bonomolo, M.; Lodato, C.; Vitale, G. A Humanoid Social Robot Based Approach for Indoor Environment Quality Monitoring and Well-Being Improvement. Int. J. Soc. Robot. 2020, 1-20. [CrossRef]

27. Mantha, B.R.; Feng, C.; Menassa, C.C.; Kamat, V.R. Real-time building energy and comfort parameter data collection using mobile indoor robots. In Proceedings of the 32nd International Symposium on Automation and Robotics in Construction and Mining (ISARC 2015): Connected to the Future, Oulu, Finland, 15-18 June 2015; Vilnius Gediminas Technical University, Department of Construction Economics: Vilnius, Lithuania, 2015; Volume 32, p. 1.

28. Jin, M.; Liu, S.; Schiavon, S.; Spanos, C. Automated mobile sensing: Towards high-granularity agile indoor environmental quality monitoring. Build. Environ. 2018, 127, 268-276. [CrossRef]

29. Yang, Y.; Feng, Q.; Cai, H.; Xu, J.; Li, F.; Deng, Z.; Yan, C.; Li, X. Experimental study on three single-robot active olfaction algorithms for locating contaminant sources in indoor environments with no strong airflow. Build. Environ. 2019, 155, 320-333. [CrossRef]

30. Rossi, S.; Staffa, M.; Tamburro, A. Socially assistive robot for providing recommendations: Comparing a humanoid robot with a mobile application. Int. J. Soc. Robot. 2018, 10, 265-278. [CrossRef]

31. Shiomi, M.; Shinozawa, K.; Nakagawa, Y.; Miyashita, T.; Sakamoto, T.; Terakubo, T.; Ishiguro, H.; Hagita, N. Recommendation effects of a social robot for advertisement-use context in a shopping mall. Int. J. Soc. Robot. 2013, 5, 251-262. [CrossRef]

32. Xu, H.; Huang, Q.; Zhang, Q. A study and application of the degree of satisfaction with indoor environmental quality involving a building space factor. Build. Environ. 2018, 143, 227-239. [CrossRef]

33. Geng, Y.; Lin, B.; Zhu, Y. Comparative study on indoor environmental quality of green office buildings with different levels of energy use intensity. Build. Environ. 2020, 168, 106482. [CrossRef]

34. Dunleavy, G.; Bajpai, R.; Tonon, A.C.; Cheung, K.L.; Thach, T.Q.; Rykov, Y.; Soh, C.K.; de Vries, H.; Car, J.; Christopoulos, G. Prevalence of psychological distress and its association with perceived indoor environmental quality and workplace factors in under and aboveground workplaces. Build. Environ. 2020, 175, 106799. [CrossRef]

35. Lu, S.; Wang, W.; Wang, S.; Cochran Hameen, E. Thermal Comfort-Based Personalized Models with Non-Intrusive Sensing Technique in Office Buildings. Appl. Sci. 2019, 9, 1768. [CrossRef] 
36. Angelova, R.A.; Velichkova, R. Thermophysiological Comfort of Surgeons and Patient in an Operating Room Based on PMV-PPD and PHS Indexes. Appl. Sci. 2020, 10, 1801. [CrossRef]

37. Jain, S.; Garg, V. A review of open loop control strategies for shades, blinds and integrated lighting by use of real-time daylight prediction methods. Build. Environ. 2018, 135, 352-364. [CrossRef]

38. Bellia, L.; Fragliasso, F.; Riccio, G. Daylight fluctuations effect on the functioning of different daylight-linked control systems. Build. Environ. 2018, 135, 162-193. [CrossRef]

39. De Vries, A.; Souman, J.L.; de Ruyter, B.; Heynderickx, I.; de Kort, Y.A. Lighting up the office: The effect of wall luminance on room appraisal, office workers' performance, and subjective alertness. Build. Environ. 2018, 142, 534-543. [CrossRef]

40. Zanon, S.; Callegaro, N.; Albatici, R. A Novel Approach for the Definition of an Integrated Visual Quality Index for Residential Buildings. Appl. Sci. 2019, 9, 1579. [CrossRef]

41. Mantha, B.R.; Menassa, C.C.; Kamat, V.R. Robotic data collection and simulation for evaluation of building retrofit performance. Autom. Constr. 2018, 92, 88-102. [CrossRef]

42. Powers, A.; Kiesler, S.; Fussell, S.; Fussell, S.; Torrey, C. Comparing a computer agent with a humanoid robot. In Proceedings of the ACM/IEEE International Conference on Human-Robot Interaction, Arlington, VA, USA, 10-12 March 2007; ACM: New York, NY, USA, 2007; pp. 145-152.

43. Bainbridge, W.A.; Hart, J.; Kim, E.S.; Scassellati, B. The effect of presence on human-robot interaction. In Proceedings of the RO-MAN 2008-The 17th IEEE International Symposium on Robot and Human Interactive Communication, Munich, Germany, 1-3 August 2008; pp. 701-706.

44. Frontczak, M.; Wargocki, P. Literature survey on how different factors influence human comfort in indoor environments. Build. Environ. 2011, 46, 922-937. [CrossRef]

45. Beranek, L.L.; Blazier, W.E.; Figwer, J.J. Preferred noise criterion (PNC) curves and their application to rooms. J. Acoust. Soc. Am. 1971, 50, 1223-1228. [CrossRef]

46. DIAL. DIALux Evo 8.2, Professional Lighting Design Software. 2018. Available online: https://www.dialux. com/it-IT (accessed on 27 October 2020).

47. Robotics, A. NAO Robot. 2015. Available online: https://www.softbankrobotics.com/emea/en/nao (accessed on 27 October 2020).

Publisher's Note: MDPI stays neutral with regard to jurisdictional claims in published maps and institutional affiliations.

(C) 2020 by the authors. Licensee MDPI, Basel, Switzerland. This article is an open access article distributed under the terms and conditions of the Creative Commons Attribution (CC BY) license (http://creativecommons.org/licenses/by/4.0/). 